\title{
Institutional Basis: the Prerequisite for Farmer' Cooperation and Agricultural Land Transfer
}

\author{
Xin Chu ${ }^{1, a}$ Danni Zhao ${ }^{2, b}$ \\ ${ }^{1}$ College of Management, Wuhan Donghu University, Wuhan, Hubei, China, 430212 \\ ${ }^{2}$ College of Foreign Language, Wuhan Donghu University, Wuhan, Hubei, China, 430212 \\ aemail, bemail,
}

Keywords: Institution, Cooperation, Cost, Agricultural Land Transfer

\begin{abstract}
System is well known for the common body of rules, according to its produce and enforceable manner, the system can be divided into internal and external systems. People usually need to have institutional cooperation framework, the type of cooperation between different social systems upon which the establishment is different. This paper attempts to use two different types of systems to analyze in traditional and modern society, the farmer cooperative based production and operation system, and pointed out that in its institutional deficiencies in the system only on the precondition that the plight of farmers is difficult Cooperation to be perfect, to be truly effective in promoting cooperation between farmers and promote circulation to be reasonable for the current agricultural land.
\end{abstract}

\section{Introduction}

In the current research problems in rural China, farmers on cooperation, transfer of agricultural land subject flurry of controversy and therefore lead to a lot. At issue is whether farmers really have the ability and prospects of cooperation, the feasibility of the transfer of agricultural land in rural China, rationality and validity. In particular, as some scholars into the countryside, carried out a variety of rural construction, they not only became the verification of various theoretical assumptions of the experiment, but again provides a platform for discussion. About the views of farmers' cooperative, so probably can be divided into two categories: the ability to kind of farmer cooperative and prospects are more optimistic, it is based on the "rational peasants" theory, Theodore Schultz, Samuel L .Popkin and other beings who hold this theory; another view compassion that farmers can not cooperate much meaning into steel, its main theoretical basis but also from abroad, by Scott (James Scott), et al. Beginning of "moral smallholder On" or "On the survival of small farmers." "Farmers can not cooperate on" One inference result is that the government must re-organization of farmers. China on cooperation of farmers, the 1930s the development of Rural Construction in Zouping County, Shandong Liang Shuming think, the biggest drawback is the lack of Chinese peasant spirit of equal consultation and ability, Mr. Cao Jinqing remark that the true, and clearly Chinese characteristics of small farmers is "Decentralization."

This article from the perspective of institutional cooperation to discuss the issue of farmers, and tried to apply to the current circulation of agricultural land in the field. New institutional economics, the system can be divided into two internal systems and external systems, in different societies, nature and operating characteristics of the two systems are very different. In traditional society, farmers' cooperative is more dependent on the internal system, while people living in modern society are more external cooperation on the basis of the system. The reason why there is no shortage of traditional social model of cooperation, in that it was set with the society to adapt, improve the internal system; on the contrary, after nearly a century of the modern movement, the current rural cooperative for showing the characteristics of the two sides: on the one hand, modernization has brought new social relations and institutional framework, reducing the cooperation in the past many restrictions in time and space; on the other hand, since the conventional system and the support of such a system on the basis of changes have taken place, the modernization process, but also the traditional culture the digestion process. The old system was 
destroyed, the new system has not been established and this "institutional vacuum" caused the current cooperation the plight of farmers.

\section{The Analytical Framework based on the New Institutionalism}

People tend to live together and to cooperate in the production areas of life. When cooperation, the situation will be better than their non-cooperation, the fact that game theory has been analyzed, the extreme situation like it is well-known so-called "Prisoner's Dilemma" (prisoners' dilemma). System behavior is the rule, and thus become a means of guiding the movement of people, they have been proven useful in the past, but also when people pursue their personal goals and interaction with others are necessary. In this regard, the system is from the past era experience stored up "knowledge repository." To ensure that cooperation is inseparable from the system, people usually need to have international cooperation institutional framework. This is because the system can increase the opportunities for mutually beneficial cooperation, and coordination between each other, in order to prevent confusion and arbitrary behavior of participants, and thus build trust between each other. In addition, the system can reduce the people in search of knowledge on the consumption behavior of each other to provide predictability, provide a method of determining the structure of social interaction and it is because of these features of the system, the American Philosophical - psychologist Ann Di. Clark (Andy Clark) recently said to be a system to provide for the study of human choice and "external bracket." According to their different ways to produce and enforceable manner, the system can be divided into internal systems and external systems. Internal systems within groups with experience evolution rules applied laterally between parallel body, in most communities, the majority of the internal system to guide the behavior of its members, the punishment for violations is decentralization, community feedback manner to implement ; on the contrary, the external system is composed of a main body designed, rely on political action and social rules imposed by the above communities, it always implies some kind of top-down hierarchy, relying on formal, organized the mechanisms for implementing the penalties for violators. Whether it is internal system or external system, the basis of its production and plays a role in both their social - political - economic structures inseparable. In the traditional society to a modern society in the transition process, due to the nature and the structure of society have undergone a corresponding change in the internal system and the external system also will be changed, and therefore on the basis of cooperation has also been carried out in different forms content and features.

\section{The System Resources of Traditional Farmers' Social Cooperation}

"Mutual repaired" farmers traditional society in the long and arduous life condensed out of natural simple exchanges relations, but also for the main content of the alleged Road Scholar native virtues. This spirit of cooperation on the performance of the clan is the most typical form of cooperation for the community, such as agricultural production, au pair, borrowing funds; the presence of ancient rural land circulation, merger, leasing; see the establishment of green associations, water Association and the maintenance of public order village Union teams; even commercial networks such as merchants and Shanxi in the country composition, cannot be separated from the blood and combined with geo-up "insiders" loyalty. Traditional farmers' era of cooperation, is based on the Confucian-called "kiss" concept and that is basically the extent of genetic and geographical closeness by a predetermined decision depth of cooperation. High degree of closeness of people, the possibility of cooperation is high, and vice versa. Obviously, for the occurrence of such cooperation, the traditional Confucian ethics and the prevalence of age rites, constitutes a corresponding culture, integrity built on the premise of each other "family", but also strengthened the ceremony. This social nature constitutes cultural conditions inherent system was established and the corresponding social basis. Internal systems can be divided into the habit (conventions), internalized rules (internalized rules), customs and manners (customs and good manners), and several other levels, it is often through diet, education and experience acquisition rules, and transformed into personal preferences, consistently applying these rules, gradually became a convention system. Thus, in the 
strife, so that people from instinct, short-sighted opportunism of the victims, to reduce conflicts and coordination costs of people. In addition, the system also has a joint inherent advantage that they can be flexibly applied to a small amount of a changing environment. Therefore, there is a custom internal systems appropriate punitive measure according to the specific interpretation and environmental capacity, which often can sometimes compensate for their deficiencies in clarity and transparency on. Because of this, the internal system is often known as the "cultural glue." Whether it is from its creation or execution, the internal system has low cost and high flexibility. These features combined with the kind of far from being fully differentiated traditional society to adapt; at the same time, also determines the characteristics of partner organizations within the system based on that, because at that time in rural areas still remain in the traditional land system of state and social structures, farmers' cooperative organizations can use common traditional social relations in the countryside. Cooperation can only be built on the blood and geographical basis, yet few edge-based industry cooperation. There are two reasons, one was mostly self-sufficient in agricultural production, there is no large-scale division of labor and exchange; the second is related to the inherent limitations of the system functioning. Internal system in order to play a role, it must be a distinction between internal and external people. Xenophobic and small-scale system is a necessary condition for the internal functioning (such as a tooth for a tooth, exile, reputational damage). Informal system of internal economic development can only be pushed to a certain level and cannot continue to expand. Thus, the strong regional cooperation and mutual assistance, and thus form a relatively closed production circle of farmers and living area.

\section{The New Cooperation Forms Brought by the Market Economy}

Made tough in the late 1970s is that market reforms in the economic field with the market economic system gradually replaced gauge economic planning system. Reform of breaking the shackles of the old rules of personal freedoms, individual farmers in accordance with its own reality to organize their lives and production, one suddenly becomes "rational" together. Money market economy is the most important symbol and it is a universal concern, all the nature and uniqueness of the number of inquiries about a value, so people are composed of an anonymous individual society, modern spirit change more and more skilled in computing. Currency economy calculation accuracy and the natural sciences practice echoes ideal type of life: the whole world into a mathematical problem, the placement of the various parts of the world in this mathematical formula, everything is predictable among. This feature constitutes unique social qualities of modern society and with its corresponding institutional foundation is the external system. Although the internal rules are effective in most cases, but in fact, all large and complex society has adopted the external system. This is because, in a complex mass society cannot exclude all the internal system of opportunistic behavior. One reason is that people often every day, and many different people, and never even to seek a face, and will not meet again strangers' transactions that tend to be disposable. Many informal punishments in preventing opportunistic behavior are not valid, therefore, to guarantee in a complex modern society, the superiority of formal rules is obvious. After exceeding the internal system can achieve the level of external institutions and governments play a protective role on the show out of scale and to ensure that all entrants have a fair and open market opportunities. For modern market in terms of its infrastructure needs are formal punishment, rather than informal discrimination, among other measures. In addition, in order to create an open and broader, more dynamic on the division of labor, some designed formal legal and judicial system is a more formal performance.

Market economy and its new social structure brought create a more open, integrated society, its rise to break the plight of two traditional small farmers to cooperate when: one living in their own self-contained natural economy of traditional farmers, dependence on the outside world is very small, it is difficult to produce cross-regional, cross-industry cooperation desire; on the other hand and more important reason is that - earnings cooperation mainly by reducing the unit production cost to produce. Therefore, the size of the benefit of cooperation depends on the size of the production scale. However, the traditional small-scale farmers cannot create jobs in such a scale. First, the market economy requires the establishment of commodity trading in the division of labor 
based on, which caused the differentiation of different occupations and different sectors of society and this will be cooperation among different groups. We can say that the development of a modern market economy cooperative organizations, and to provide the institutional guarantee.

Some commentators have suggested that, in the planned economy period, the farmers had demonstrated an unprecedented spirit of cooperation and we can see a strong government is necessary for farmers' cooperation. In this regard, I do not agree, first of all, is to establish a cooperative relationship between the different independent body, otherwise it does not matter what the cooperation; secondly, cooperation should be based on voluntary individual. So, if there is a genuine partnership between the farmers could have questioned that period. Heavy overriding priority of development policy, "catch-up strategy" that farmers once again become a fully-fledged vulnerable persons living in a self-interests in the system are not effectively protected society, a variety of "loophole" naturally became helpless farmers alone "rational move." On the other hand, from the perspective of a more ambitious process of modernization of state and society relations point of view, as a latecomer exogenous China, through strong government planning and control in order to obtain a stable social order and economic development, but such a consequence is the loss of the social space of their own free development, become appendages country, not only the farmers, all the laborers had to be in force under the national "cooperation." In sub-contracting field as the beginning of reform of course cause fragmentation and the increasingly obvious profit-driven production, but it is not farmers, "uncooperative" root causes. Income small-scale production on the basis of cooperation brought about by subtle, and because the regular, cooperating with the modern market economy system environment also is not widely deployed in the countryside, in this case, between farmers if agriculture cooperation on production to be generated transaction costs is undoubtedly relatively large, compared with the income generated by cooperation and soar, so, in a certain stage of "non-cooperation" is also rational. Farmers market is not atomized culprit, but to create a new cooperative ties, the cooperation that the failure to appear widely in the countryside just that the rural market is not complete. The so-called market, it is above all an equal trading relationship between an independent property rights, unclear property rights will not be able to make optimum configuration elements, resulting in economies of scale could not come, there is no economic basis for cooperation, which is in the most obvious is the rural land system. Market economy and the rule of law is also a credit economy. Legal system is not perfect and abiding sense of indifference and the decline of the rural traditions of coexistence, cooperation extended lack of strong support system. 1980s market-oriented reforms to the society and its individuals brought profound changes, and even allow supporters of the reform was surprised - Society showed great vitality, direction and logic of its development is far from can only rely on administrative orders to plan, this trend for the market requirements of social legislation in many areas of the current, we are still in the planned economy under the logic of behavior, between the inherent requirements of the market and the formation of a rigid system of enormous tension this is our current society where embarrassment. China also is in a transition period, the current theme of running society is still far from complete sense logic of the market, specific to rural society, it is strange shadow mottled. Establishment of a modern market ethos fit, other than in institution-based partner organizations, is the way out of the current farmers' cooperative, but also affect China's rural agricultural land transfer is successful, adequate, reasonable and effective prerequisites.

In addition, one important fact is that, even in today's farmers cannot seem cooperation among such cooperation actually happened. For example, in the plains north, the annual wheat harvest in May and June, shuttle, such as hemp harvester in the field between the day and night work, and with the change of season advancing from south to north, cross-operating; the majority of rural areas a large amount of agricultural land are circulation, trade, along with a wide range of other factors of production flow, productivity objectively steadily increased, farmers in the region to achieve greater cooperation. So when we are talking about is not in the farmers' cooperative, as well as how well the cooperation, you can not only look beyond whether farmers in the area of social life itself in the establishment of a variety of production and living tissue; Similarly, not in the traditional when social comparison, because the organization saw some traditional societies ceased 
to exist, so come to the market economy led to the farmers, "atomic" and therefore difficult to work conclusion. A different perspective, you will find that contains the transfer of agricultural land, including rural, farmers occurred in the current cooperation in market economy conditions, the establishment of institutional cooperation in modern society. An important feature of modern society is to break the original kind of comprehensive relations between people, in an anonymous society transformed into a role relationships, people's behavior is controlled by external institutions and rules to coordinate in order to achieve more a wide range of cooperation, which is the transfer of agricultural land institutional infrastructure.

\section{Acknowledgements}

Fund Project: This work was supported by the grants from Hubei Provincial Collaborative Innovation Centre of Agricultural E-Commerce (under Construction).(Wuhan Donghu University Research [2015] No. 11 Document)

\section{References}

[1] Cao Jinqing. "Yellow River in China" Shanghai Literature and Art Publishing House, 2000 edition

[2] Kasper Shi Manfei: "Institutional Economics - social order and public economics" Commercial Press, 2002, pp. 110-137.Electronic Industry, Vol. 6 (2014) No 53, p.25-26 